\title{
MODERN GLASS TECHNOLOGY
}

$\mathrm{B}^{\mathrm{o}}$ OTTLES of skin, gourd or calabash (tree or climbing plant, the fruit-shell of which has been emptied and dried), alabaster, ivory and even beaten gold, have been in use down the centuries, things both of beauty and utility; many relics are with us to-day, in museums and elsewhere, all over the world. But for several millennia the most favoured bottle material has been ordinary glass, starting with the eraftsmain glass-blower (still with us in many specialized pursuits, particularly concerning apparatus for scientific laboratories), graduating by moulding processes ultimately to the fully automatic bottle-making machines operating to-day. It may not be generally realized that glass as such is unique matter. It is not a true solid, but, according to C. L. Boltz in an interesting article in Catalyst, Vol. 12 (Industrial Journal of Shell Chemical Co., Ltd., London, Spring 1964), " . . . scientifically ... a super-cooled solution that still flows over a long period of time .... it is not crystalline in tho serise that atoms are arranged in regular geomotrical patterns ... it is mainly amorphous, shapeless, and shatters randomly when it is abruptly broken".

In the early days glass products were usually coloured green, amber, blue or ruby, due to impurities such as iron, mangainese, etc. It was not until 1908 that the first colourless glass bottles were produced in London. "The first university department in tho world for the scientific investigation of glass technology was formed at Sheffield under Prof. W. E. S. Turner and has achieved international recognition. The use of polarized light for the detection of stress-lines in bottles and the importance of the glass surface in the retaining of strength are just two of the developments that have led to to-day's industrial glass technology." Apart from Sheffield, glass technology is now also the concern of the British Glass Industry Research Association (formed as recently as 1955) and the Glass Manufacturers' Federation.

Such has been the phenomenal advance in research and manufacturing techniques in recent years that it is estimated that, in Britain alone, some 4,500 million glass containers are manufactured per annum. Collaterally there has been the challenge of tin in replacing glass containcrs and more recently some of the thermoplastics, notably polyothylene. But in quite a diffurent and porhaps more refined sphere of glass technology comes the highly skilled and expert precision operations of those firms conccrned with manufacture of optical glass.

The word 'Jena' conjures up many memories, past and present, of lenses, microscopes and other optical instruments, and the bi-monthly Jena Review (VEB Carl Zeiss Jena, English translations available), now in its ninth yoar, makes available much technical information of pressint-day value to optical physicists and others concerned with precision optical equipment in this and allied fields. The issue No. 2, 1964, contains, inter alia, informative articles on synthetic crystals of fluorite and salt from melts, alum and quartz from solutions made in Jena; on objective photo-electronic testing or precision glass scales; preparation of fibre surfaces for eloctron microscopic examinations; spectrophotometry in the near infra-red with the ' $U R$ 10' Spectrophotometer, and linearity tests of other infra-red instruments. This review is an attractive publication and yet another example of a high-quality house journal.

\section{KARMAN VORTEX-STREETS IN EARTH'S ATMOSPHERE}

\author{
By Dr. K. P. CHOPRA \\ Melpar Inc., Falls Church, Virginia \\ AND \\ L. F. HUBERT \\ U.S. Weather Bureau, Washington, D.C.
}

\begin{abstract}
HE mechanism for the production of eddies on the planetary scale (cyclones) and those on the microscale (turbulent eddies) have been extensively investigated. The recent weather satellite results ${ }^{1}$ have revealed the existence of the mesoscale eddies which are on an intermediate scale that is too small to be delineated by the standard weather observation network and are too large to be seen by an observer on the ground or even pictured from a highflying aircraft. These eddies, shown in Fig. 1, are formed in the wakes of islands and have been observed to persist at downstream distances of a few hundred miles. They are made visible by patterns in the stratocumulus clouds lying beneath a strong inversion about $0 \cdot 5-1$ mile above the ocean surface. 'These eddies have a band-width of the order of the cross-stream diameter of the island, and bear a cortain resemblance to the classical von Kármán vortexstreet pattern shown in Fig. 2 and observed in the laboratory investigations of wakes behind obstacles to fluid flow. The purpose of this communication is to examine the properties of these eddies in the light of this apparent resemblance.
\end{abstract}

Viscosity plays two parts in the flow pattern of a Kármán vortex-street. First, it leads to the formation of the boundary layer in which vorticity is generated and the vortex-pairs are formed, the vortices being shed alternately near each edge of the obstacle. Secondly, the strength of the eddies is dissipated by the mechanism of diffusion; the size of an eddy increases and its strength decreases as it propagates downstream, until its region of influence overlaps that of a neighbouring eddy of opposite circulation. In all other respects, the fluid may be regarded as perfect (inviscid).

The rate $N$ of shedding of the eddy pairs is given by:

where

$$
N=u_{e} / \alpha
$$

$$
u_{e}=u_{0}+(k / 2 \alpha) \tanh (\pi h / \alpha)
$$

is the speed of propagation downstream of the eddies in a co-ordinate system fixed to the obstacle, $u_{0}$ is the spced of the undisturbed flow, $\alpha$ is the longitudinal spacing (pitch) between two eddies of similar circulation of strength $k$. 